\title{
A Qualitative Comparison of Techniques for Student Modelling in Intelligent Tutoring Systems
}

\author{
Sai Sruthi Gadde ${ }^{1}$, Venkata Dinesh Reddy Kalli² \\ (CVG, Medtronic, Tempe, USA ${ }^{1,2}$ )
}

\begin{abstract}
Wise Tutoring Systems (ITS) are intuitive learning conditions dependent on guidance helped by P.C.s. The insight of these frameworks is, to a great extent, ascribed to their capacity to adjust to a particular understudy during the educating cycle. As a rule, the variation cycle depicts by three stages: (I) getting the data about the understudy, (ii) preparing the data to introduce and refresh an understudy model, also, (iii) utilizing the understudy model to give the transformation. In this paper, we considered viewpoints related to understudy displaying (S.M.) in Intelligent Tutoring Systems. First, we make a subjective examination of two procedures: Bayesian Networks (B.N.) and Case-based Reasoning (CBR) for S.M. We apply the two strategies to a contextual analysis concerning the advancement of an ITS for e-learning in the clinical space. At last, we talk about the outcomes acquired.
\end{abstract}

Index Terms: Bayesian Networks, Case-based Reasoning, Intelligent Tutoring Systems, Student Model.

\section{INTRODUCTION}

Versatile educational plan sequencing and intuitive issue settling support are significant parts of intelligent tutoring systems (ITS). Understudy displaying utilizes predominantly together to adjust the ITS to every understudy. S.M. includes making a singular model for every understudy that distinguishes the current information on the understudy and adjusts the learning succession.

Some understudy models work to perceive understudy plans or arrangement ways [1]; some work to assess understudy execution or critical thinking aptitudes [2]. Furthermore, some are for depicting imperatives that the understudy has abused [1] [2]. However, the explanation for one inquiry is must construct another understudy model: what parts of the understudy should we model in a particular shrewd mentoring framework?

This paper addresses what to display and how to separate the understudy model into segments regarding a Savvy Tutoring System for preparing in irresistible infections, ITS-TB. Two demonstrating procedures utilized are Case-Based Thinking and Bayesian Networks. We investigate the understudy presenting measure with these procedures, and we make a subjective correlation of B.N. and CBR.

\section{MODELING TECHNIQUES}

\section{A. BAYESIAN NETWORKS}

Mathematical strategies for thinking under vulnerability have been applied to understudy demonstrating, particularly in the last, not many a long time. Mathematical methods, for example, Bayesian Networks (B.N.) [4], the Dempster-Shafer hypothesis of proof [19], and fluffy rationale [20], are utilized for creating understudy models. Different methods, albeit computationally modest (e.g., the model following approach [21]), can record what an understudy knows and not its conduct and attributes. B.N. is the most extensively utilized methodology for thinking under vulnerability in learning conditions. Utilizing earlier and contingent probabilities appended to each hub, it is conceivable to engender changes in likelihood esteems on receipt of proof. The easygoing data encoded in B.N. encourages examining activity groupings, perceptions, results, and expected utility [5].

A few creators in various zones have investigated the utilization of Bayesian Networks to speak to understudy models. Mayo [6] groups Bayesian understudy displaying approaches dependent on how the organization's structure and earlier, contingent probabilities are evoked. Mayo recognizes three kinds of Bayesian understudy models: master drove, productivity-driven, what's more, information-driven. Master driven models use specialists to determine the organization's structure and its relating beginning earlier, contingent probabilities. For the most part, coming about organizations contain many factors, making it hard to assess the model. Proficiency driven models limit the structure of the organization to amplify productivity. There are a few chances with this methodology, for example, misrepresenting the model or potentially presenting wrong suspicions. Finally, information-driven models use information from past tests and pre-tests to create the organization and its probabilities. 
A few frameworks utilizing Bayesian Networks in understudy demonstrating are OLAE, POLA, ANDES, and others [7]. These frameworks store data about understudies in various information territories. The motivation behind the OLAE framework [8] is the understudy model evaluation. It utilizes Bayesian Networks to notice understudy conduct and figure the probabilities that the understudy knows and uses every one of the standards in the guaranteed information area. Also, it acts when the understudy has tackled the issue. POLA [1] broadened the OLAE framework. It decides the guidelines known and the street, followed by the understudy in critical thinking. Finally, ANDES [9] decides the understudy's earlier probabilities of knowing many essential information things.

\section{B. CASE BASED REASONING}

Case-based thinking (CBR) is a generally new problem-solving system and A.I. method. CBR is a viable worldview for critical thinking from numerous perspectives. Rather than depending entirely on the comprehensive information on an issue space or making a relationship about the summed up connections between issue descriptors and ends, it can use the detailed information on already experienced, solid issue circumstances or cases [3].

The CBR worldview covers a scope of various techniques for getting sorted out, recovering, using, and ordering the information held in past cases. Cases might be put away as independent information units or isolated into subunits and dispersed inside the information structure. Cases might be filed by a prefixed or open jargon and inside a level or progressive list structure. A past case arrangement might be straightforwardly applied to the current issue or adjusted by contrasts between the two cases. The coordinating of cases, the transformation of arrangements, and gaining from an encounter may be guided and upheld by a profound model of general area information, by more shallow and ordered information, or just be founded on an obvious, syntactic closeness. CBR techniques might be independent and programmed, or they may associate vigorously with the client to help and guide his decisions. Some CBR techniques accept a fairly huge measure of generally appropriated cases for its situation base, while others are in light of a more restricted arrangement of regular ones. Past cases might be recovered and assessed successively or in equal.

This method is basic also, doesn't need an intricate deduction calculation. Moreover, it tends to be applied to get different sorts of data identified with the student's information, such as the information level, the capacities (relationship and variation), and the student's arrangement. CBR is useful in instructing, arranging, plan, and argumentation. In [17], CBR is used to build only the information segment of the understudy model. However, different methodologies don't worry about preparing, but it tackles issues found in a conventional instructing measure.

\section{III.ITS-TB: A CASE STUDY}

We are building a wise coaching framework, ITS-TB, which helps clinical understudies in critical thinking and choicesmaking. In the below table 1 structure of the course is explained.

TABLE 1

HEALTH CARE COURSE

\begin{tabular}{|c|c|c|c|c|c|c|c|}
\hline Asignature & $\begin{array}{l}\text { Duration } \\
\text { (Months) } \\
\end{array}$ & Topic & Weights & $\begin{array}{l}\text { Duration/topic } \\
\text { (Months) }\end{array}$ & Subtopic & Weights & $\begin{array}{l}\text { Time } \\
\text { (days) }\end{array}$ \\
\hline \multirow{8}{*}{ PYC } & \multirow{8}{*}{5.} & \multirow{8}{*}{$\begin{array}{l}\text { Non } \\
\text { infectious } \\
\text { disease }\end{array}$} & \multirow{5}{*}{$\lambda=0.4$} & \multirow{5}{*}{3.} & Theorical Basis & $\mathrm{W}_{11}=0.2$ & 4.5 \\
\hline & & & & & Risk Factors & $\mathrm{W}_{12}=0.25$ & 4.5 \\
\hline & & & & & Clinical isues & $\mathrm{W}_{13}=0.25$ & 50 \\
\hline & & & & & Operative Plans & $\mathrm{W}_{14}=0.3$ & 30 \\
\hline & & & & & Theorical Basis & $\mathrm{W}_{15}=0.3$ & 3 \\
\hline & & & $\lambda=0.6$ & \multirow[t]{3}{*}{2.} & Risk Factors & $\mathrm{W}_{16}=0.3$ & 7. \\
\hline & & & & & Clinical isues & $\mathrm{W}_{17}=0.2$ & 26.5 \\
\hline & & & & & Operative Plans & $\mathrm{W}_{18}=0.2$ & 23.5 \\
\hline
\end{tabular}

Every understudy has specific information, capacities, inclinations, and educational foundation. Various purposes of the understudy model in ITS-TB are: 


\section{International Journal of Advanced Research in Computer and Communication Engineering}

Vol. 9, Issue 11, November 2020

DOI 10.17148/IJARCCE.2020.91113

- To decide whether the understudy is prepared to proceed with the next educational program theme and pick this subject.

- To create clarifications as indicated by the understudy information.

- To encourage and help the understudy. The mentor doesn't intrude on the understudies now and again and permits them to learn from their mix-ups.

- To create issues as indicated by the understudy information level. When the frail purposes of the understudy are recognized, the framework produces an issue. This issue is tackled all the while by the master module to analyze the understudy arrangement. In this sense, every understudy associated with the framework will take care of many issues adjusted as far as anyone is concerned level.

- To produce a good training technique as indicated by the understudy information.

\section{Student Model Content}

An exhaustive understudy model ought to contain data about the past understudies' information, the understudy's progress, inclinations, interests, objectives, individual data, what's more, some other data identified with the understudy. Because of the reliance upon the subject area, the substance held in understudy models comprises of two sections:

- Domain-Specific Information (DSI): it is also known as the Student Knowledge model (SKM), which speaks to an impression of the understudy's state and level of information on a specific subject area.

- $\quad$ Domain autonomous data (DII): it is marginally not the same as framework to framework. The area free data about an understudy may incorporate learning objectives, intellectual aptitudes, inspiration state measures, inclinations about the introduction technique, authentic and memorable information, etc. We propose an understudy model that incorporates individual and intellectual qualities gathered in a segment named information part. This segment contains data identified with the (1) information level of the understudy, (2) individual data, (3) learning inclinations, and (4) mental qualities.

\section{2. $\quad$ Student Modeling with Bayesian Networks}

To develop the Bayesian Network for displaying the understudy, we use GENIE [11], a turn of events climate for building graphical choice, hypothetical models. This device actualizes a few B.N. deduction calculations, counting bunching, and stochastic calculations.

In the understudy model, the understudy's intellectual condition's deduction is made from two sections: the past information about the understudy and the understudy's conduct during the cooperation with the framework [12], both including vulnerability. Methods make the determination measure for spreading the probabilities contained in the hubs of the organization. The ideas corners speak to the information level that the understudy has obtained in each view of the instructional practice. The educate idea hubs demonstrate the evaluation of practicality for contemplating an idea in the instructional exercise. The theme hubs store the information score obtained by the understudy in a particular instructional exercise subject. Every intersection has two states: "known" or "obscure," which speak to the information level obtained by the understudy and the related likelihood, separately. Figure 1 shows the Bayesian organization utilized.

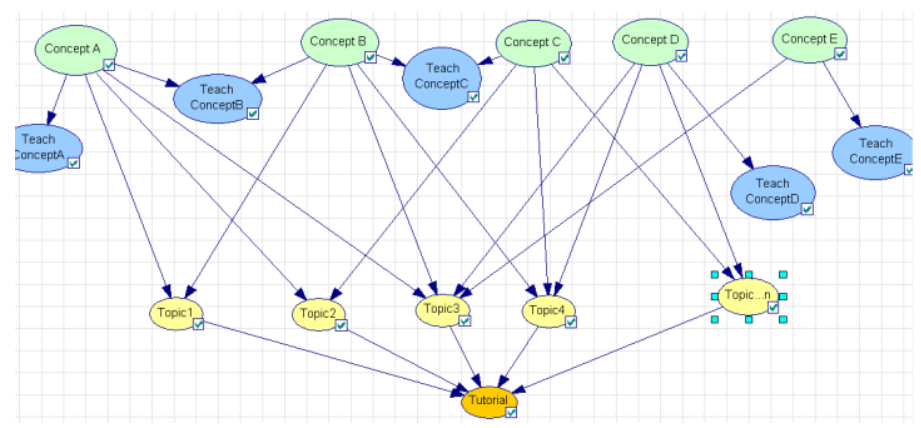

FIGURE 1. BAYESIAN NETWORK

Figure 2 speaks to the B.N. for every understudy and the set of restrictive probabilities. The estimations of the possibilities were acquired from proof by likelihood engendering. Each ID relates to one understudy, the course subjects' information level, and his profile as indicated by his information area. 


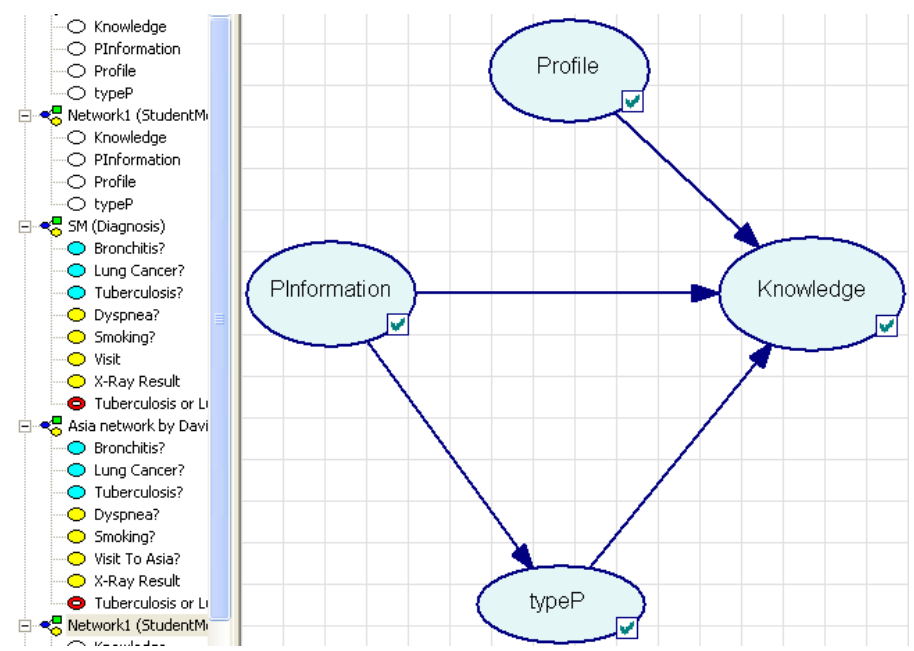

FIGURE 2. STUDENT KNOWLEDGE

\section{3. $\quad$ Student Modeling with Case-Based Reasoning}

Our methodology for understudy displaying with CBR incorporates a portrayal of the information and thinking of the understudy, also, the way how the understudy gains new knowledge all together to perform innovative learning. The understudy model worked with CBR is organized as a multi-specialist framework [13] and follows the steps of a CBR cycle.

- $\quad$ Retrieval Phase: When the understudy associates with the framework unexpectedly, the data is obtained. The framework models the understudy as another case and looks for an illuminated issue by contrasting this new case and the current case base. The framework utilizes a table of likeness to choose a comparable subject ideally. By and large, the calculation for figuring likeness utilizes a basic Nearest Neighbor Algorithm [14]. The calculation recipe is :

$$
\text { Similarity }(N, S)=\sum_{i=1}^{n} f\left(N_{i}, S_{i}\right) \times w_{i}
$$

where:

$\mathrm{N}$ is the new case (new student)

$\mathrm{S}$ is the source case (past student history)

$\mathrm{n}$ is the number of feature in each case

$\mathrm{i}$ is an individual feature from 1 to $\mathrm{n}$

$\mathrm{f}$ is a similar function for the element $\mathrm{I}$ in patients $\mathrm{N}$ and $\mathrm{S}$

$\mathrm{W}$ is the weight of component I

The Procedure Matching is executed to check the comparing highlights in the cases put away. A coach specialist plays out this undertaking. This methodology is introduced in figure 3.

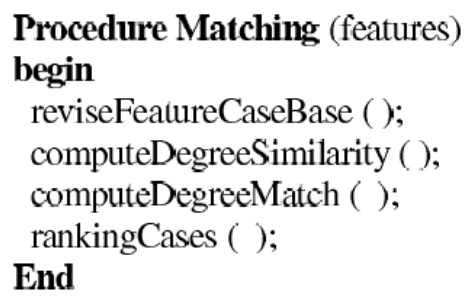

\section{FIGURE 3. PROCEDURE MATCHING}

- $\quad$ Reuse Phase: If a comparable case is chosen, at that point, the framework gauges the level of the likeness of the looked through the issue by utilizing fixed qualities as limits. On the off chance that the level of similarity is higher than the specified limit esteem, at that point, the diagnosing and comprehending strategy of the comparative case found for the situation base is applied to the enhanced one. The framework views the new case as nonexistent for the situation base and considers the new issue unique. A transformation specialist plays out this errand. In the reuse stage, five gatherings of rules are proposed: (1) dissecting the understudy's misinterpretations, (2) diagnosing the understudy's information, (3) making an ideal issue case, and (4) induction over a fragmented case.

- $\quad$ Revise Phase: The chosen case is overhauled by an transformation rule to eliminate unsatisfactory components and good conflicting qualities. The modify stage may change ascribes or values inside the matter. A direction specialist 
Vol. 9, Issue 11, November 2020

DOI 10.17148/IJARCCE.2020.91113

constrains this stage. This specialist performs two undertakings: (1) assesses the case arrangement created by reuse, and (2) fixes the case arrangement utilizing domain-specific information.

- Retain Phase: If the level of comparability is lower than the fixed limit esteem, the framework views the new case as nonexistent for the situation base and continues to hold its subtleties. The framework in this stage checks the aftereffects of the critical thinking strategy. The framework embeds them into the case base; in any case, the framework expects that the understudy doesn't perform well furthermore, gathers the understudy's confusions. Finally, the framework gives the understudy an ideal critical thinking arrangement.

\section{Implementing the CBR Student Model}

To actualize the understudy model with CBR, we have utilized CBR Works [15]. The specialist worldview [13] has been picked due to its self-rule and proactivity to assume the human function of a coach. As we expressed previously, data about the understudies are viewed as cases. Figure 4 portrays the understudy demonstrating with specialists. Figure 5 shows the idea of the supervisor. The points put away for the situation base can be in four states:

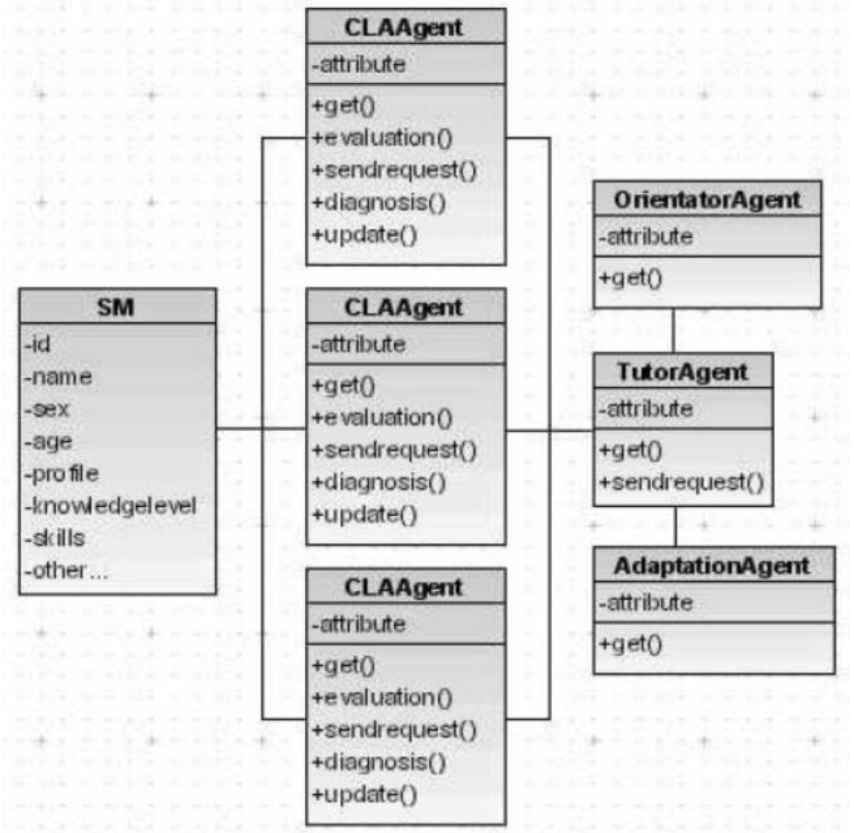

FIGURE 4. AGENTS IN CBR STUDENT MODELING

- Unfounded: Case is deficient or not yet approved. Instances of this mode won't be recovered.

- $\quad$ Confirmed: Case is finished and approved. Instances of this mode are taken into account recovery.

- $\quad$ Protected: Case is finished and approved, yet ensured against undesirable changes.

- Obsolete: Case contains old information, might be fascinating for insights. Cases in this mode are not recovered.

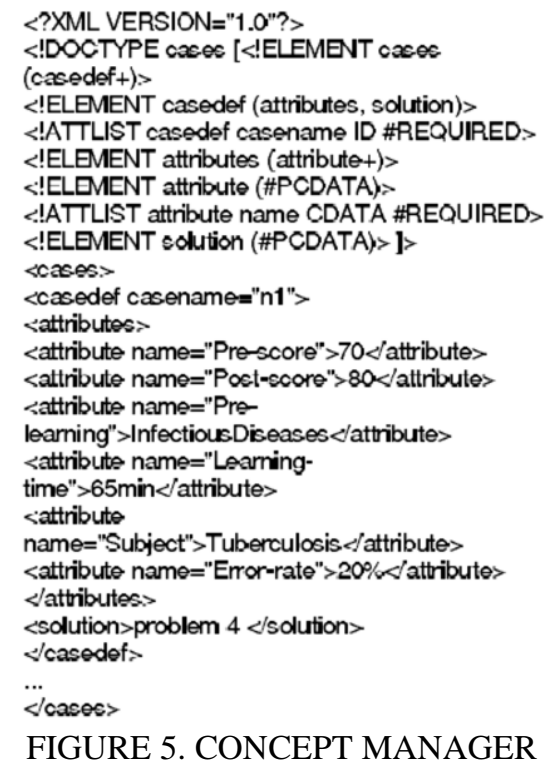




\section{International Journal of Advanced Research in Computer and Communication Engineering}

Vol. 9, Issue 11, November 2020

DOI 10.17148/IJARCCE.2020.91113

Figure 6 presents the age of another case and its expansion for the situation cushion. All the topics have been set to be in affirmed and secured mode, recovered, and tried not to alter their substance.

\begin{tabular}{||l|l||}
\hline 9. CBR-Works Case Explorer - StudentModel1 \\
\hline File Edit Model Tools Server Language Help \\
\hline \hline Case
\end{tabular}

FIGURE 6. CBR CASE EXPLORER

In the recovery cycle, the case guide makes new inquiries where new qualities are relegated to clear ideas to make another case. Besides, in this cycle, we can utilize a current issue as an inquiry. The comparability of the recovered patients is acquired by using credited based similitude. Figure 7 shows a comparable case.

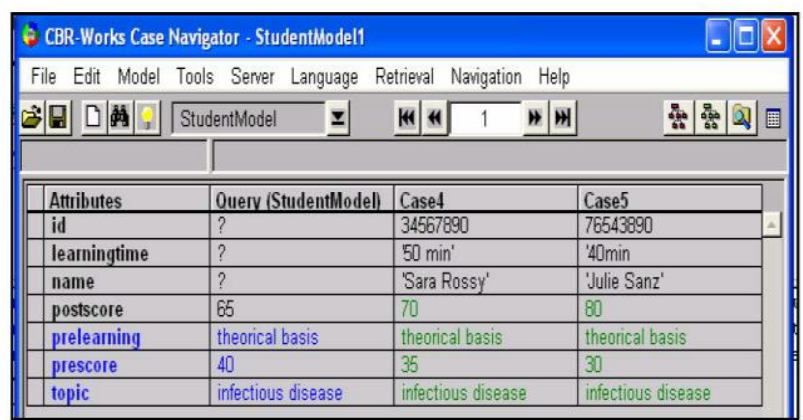

FIGURE 7. CBR CASE NAVEGATOR

After demonstrating with CBR the S.M. of ITS-TB, we understand that:

- The understudy execution assessment served to choose when to offer clues or responses if the understudy can't address an inquiry.

- The understudy answer history permits the guide to end a discourse and re-visitation of the first arrangement when the understudy couldn't proceed with a causal connection.

- The classification understudy answer, a piece of the understudy answer history, is influential in settling on distinctive retry techniques. It perceives close to misses what's more, different classifications of answers that could be recently treated as absolutely incorrect answers.

- The mentoring history kept the coach from giving a similar clue over and over.

\section{DISCUSSION}

To figure out what data should be remembered for the understudy model is a subordinate framework undertaking, we need to consider a few imperatives. The first is the idea of the area: Is it a quantitative or a subjective place? The second limitation is the structure of an instructional exercise meeting. We need to consider the understudy framework collaboration, how the framework presents the issue to the understudy, and how it can see the understudy's advancement. A third requirement is the instructional exercise choices that the framework needs to make. Does the framework need to design the educational program, switch between mentoring conventions, design coaching exchange, or give a straightforward criticism without multi-step plans? We consider CBR as a promising approach whenever it has been contrasted and B.N. in light of the results that appeared in Table 2 and clarified straightaway.

- Theoretical Basis: B.N.s have been significantly utilized in understudy, demonstrating their extraordinary flexibility and hypothetical strength. Likewise, B.N. is considered a fantastic asset to make adductive and prescient deductions. Then again, CBR is a robust worldview for critical thinking utilizing continuous learning since, each time an issue is unraveled, it is put away as a case in the CBR memory for additional utilization.

- Structure Definition: This viewpoint is one of the hardest to unravel. When utilizing B.N. is expected that the human master gives the structure of conditions and the boundaries. By and by, it very well may be outlandish for an educator to indicate the incredible number of restrictive probabilities required. It is simpler for the master to depict his feelings 


\section{International Journal of Advanced Research in Computer and Communication Engineering}

Vol. 9, Issue 11, November 2020

DOI 10.17148/IJARCCE.2020.91113

regarding informational collections put away on the off chance that bases or rules than he evaluates them in the structure of probabilities.

- Model Initialization: In B.N. and CBR, the understudies' underlying information can be obtained using past surveys or tests. A few methodologies depend on a blended instrument where B.N. and CBR are joined to procure beginning information on the understudies. In this methodology, the data essential to building the B.N. is taken from cases put away for the situation bases.

- Diagnosis Process: The likelihood engendering calculations utilize the verifiable relations of autonomy in the structure of a B.N. to compute each hub's probabilities given the proof accessible. After ascertaining these probabilities, it is conceivable to make prescient and adductive inductions. These estimations can be conveyed by applying the Bayes' Theorem, the law of aggregate likelihood, and contingent autonomy states. In this sense, the quantity of activities develops dramatically with the network's portion turning into a computational immovable undertaking. Utilizing CBR, the analytic implementation can be made more quickly, following the case recuperating cycle with closeness calculations of low multifaceted nature. Also, the deduction cycle can be practically identical to the one utilized by a human master.

- Use: CBR permits to choose the sufficient instructing procedure furthermore, simultaneously, to analyze the misguided judgments submitted by the understudies. An ITS dependent on CBR improves the accuracy at the hour of deciding the information level and the understudies' mistakes during the learning measure.

- Complexity: CBR permits simple support of the case base: adjust an activity, changing the sort of trait, adding another case, and effectively refreshing the model. A few issues found with CBR were comprehended utilizing the specialist's innovation (p.e., to deal with the enormous size of the case library in complex spaces). The trouble to get the underlying boundaries or add another hub in B.N. is more significant because of: the detailed information securing measure, the restrictive and unqualified conditions, the update of the model, and the computational intricacy of the induction calculations.

\section{IV.CONCLUSIONS}

We contrasted subjectively the understudy displaying and two procedures: Bayesian Networks and Case Base Reasoning. Bayesian Networks is a methodology extensively utilized in understudy demonstrating, yet there is a high evaluation of unpredictability in their plan. The primary explanations behind evade the utilization of B.N. are the computational unpredictability of the calculations and the trouble of the information procurement measure.

The case-based Reasoning method as a more straightforward approach for building an understudy model since it presents various favorable circumstances: (a) it is simpler to deal with, to refresh and to keep up the understudy model, advantageous for both the coach and the understudy; (b) it advances understudy reflection since they report understudy's misguided judgments and the reasons why they have occurred; and (c) it encourages the management of the understudies by empowering the mentor to have a constant and robust perspective on the understudy execution, including both quantitative and subjective data.

\section{ACKNOWLEDGMENT}

The creators need to thank mysterious commentators and Prof. Ubaldo García-Palomares for their accommodating remarks.

\section{REFERENCES}

[1]. Conati, C., Gertner, A. S., VanLehn, K., and Druzdzel, M. J. On-Line Student Modeling for Coached Problem Solving using Bayesian Networks. Proceedings of UM-97, Sixth International Conference on User Modeling, Chia Laguna, Italy, 1997, pp. $231-242$.

[2]. Katz, S., Lesgold, A., Eggan, G., and Gordin, M. Modelling the Student in SHERLOCK II. Journal of Artificial Intelligence and Education (Special Issue on Student Modeling), 3(4), 1993, pp. 495-518.

[1]. Mitrovic, A. Experiences in Implementing Constraint-Based Modelling in SQL-Tutor. Goettl, B. P., Halff, H. M., Redfield, C. L., and Shute, V.J. Eds., Intelligent Tutoring Systems. 4th International Conference on

Intelligent Tutoring System (ITS-98), San Antonio, Texas, 1998, pp. 414-423. Berlin: Springer-Verlag. (Lecture Notes in Computer Science, no. 1452.)

[2]. Ohlsson, S. Constraint-Based Student Modelling, Artificial Intelligence in Education, 3(4), 1992, pp. $429-447$.

[3]. Aamodt, A, and Plaza, E. Case-Based Reasoning: Foundational Issues, Methodological Variations, and System Approaches, A.I.Communications, 7(1), 1994, pp. $39-59$.

[4]. Przytula, K and Thompson, D. Construction of Bayesian Networks for diagnostics. IEEE Aerospace Conference Proceedings. Volume 5, 2000, pp. $193-200$.

[5]. Judea, Pearl. Decision Making Under Uncertainty. ACM Computing Surveys. 28 (1), 1996, pp. 89-92.

[6]. Mayo, M, and Mitrovic. Optimizing ITS Behavior with Bayesian Networks and Decision Theory. International Journal of Artificial Intelligence in Education. Volume 12, 2001, pp. 124-153.

[7]. Conejo, Ricardo., Millán, Eva., De la Cruz, José L., Trella, et al. Modelado del alumno: Un enfoque bayesiana. Revista Iberoamericana de Inteligencia Artificial. Volume 12, 2001, pp. 50-58.

[8]. Martín, J., VanLehn, K. OLAE: Progress toward a multi-activity, Bayesian student modeler. Proceedings of the World Conference on Artificial Intelligence in Education. 1993, pp. 410-417. 


\section{International Journal of Advanced Research in Computer and Communication Engineering}

Vol. 9, Issue 11, November 2020

DOI 10.17148/IJARCCE.2020.91113

[9]. Gertner, Abigail., VanLehn, Kurt. Andes: A Coached Problem Solving Environments for Physics. Lecture Notes in Computer Science. Volume 1839, 2000, pp. 133.

[10]. Brusilovsky, P. The construction, and application of student models in intelligent tutoring systems. Computer and System Sciences International, $32(1)$, pp. 70-89.

[11]. Laboratory Decision Systems. Genie Bayesian Network Repository. The University Of Pittsburgh. 2003. Available on http://www.sis.pitt.edu/ genie/

[12]. Wei, Fang., Moritz., Sally., Parvez, Shahida., and Blank, Glenn. A student model for objected-oriented design and programming. ACM Journal of Computing Sciences in Colleges. Volume 5, 2005, pp. 260- 273.

[13]. Wooldridge, Michael. Introduction to MultiAgent Systems. John Wiley

and Sons, 2002.

[14]. Joussellin, A., Dubuisson, B. A link between k-nearest neighbor rules and knowledge-based systems by sequence analysis. Pattern Recognition Letters. Volume 6, 1987, pp. 287-295.

[15]. Tecinno. CBR-Works. 2000. Available on http://www.aicbr. org/tools/tecinno.html.

[16]. González, Carolina., Burguillo, JC., Llamas, Martín. A comparison of Case-Based Reasoning and Bayesian Networks for Student Modeling in Intelligent Learning Environments. Source Files. (2005) . Available on:

http://www-gist.det.uvigo.es/ cgonzals/SM.zip

[17]. Shiri, M, and Aimeur, E and Frasson, C. Student Modeling by Case Based Reasoning. 4th International Conference in Intelligent Tutoring Systems, LNCS, Volume 1452, 1998.

[18]. Jameson, A. Numerical uncertainty management in user and student modeling: An overview of systems and issues. User Modelling and UserAdapted Interaction, Volume 5, 1996, pp. 193-251.

[19]. Bauer, M. A Dempster-Shafer approach to modeling agent references for plan recognition. User Modeling and User-adapted Interaction, Volume 5, 1996, pp. 317-348.

[20]. Hawkes, L.W., Derry, S.J., and Rundensteiner., E. Individualized tutoring using an intelligent fuzzy temporal relational database. International Journal of Man-Machine Studies, Volume 33, 1990, pp. 409-429.

[21]. Anderson, J.R., Boyle. Cognitive modeling and intelligent tutoring. Artificial Intelligence, Volume 42, 1990, pp. 7-49.

[22]. Anderson, J.R., Corbet. Cognitive tutors: Lessons learned. The Journal of the Learning Sciences, Volume 4 (2), 1995, pp. 167-207.

[23]. Scank, R. and Edelson, D. A role for A.I. in education: using technology to reshape education. Journal of Artificial Intelligence in Education, Volume 1 (2), 1990, pp. 3-20. 